https://doi.org/10.30910/turkjans.680034

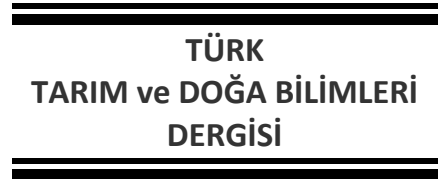

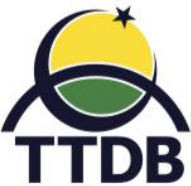

www.dergipark.gov.tr/turkjans

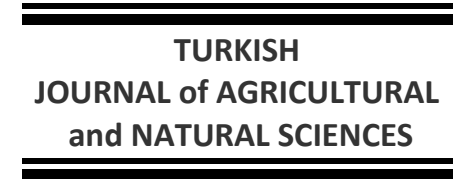

Araştırma Makalesi

\title{
Çanakkale İlinde Kanola Üretiminin Fonksiyonel Analizi
}

\author{
Arif SEMERCi* \\ Çanakkale Onsekiz Mart Üniversitesi, Ziraat Fakültesi, Tarım Ekonomisi Bölümü, Çanakkale \\ *Sorumlu yazar: arifsemerci69@gmail.com
}

Geliş Tarihi: 13.09.2019

Düzeltme Geliş Tarihi: 06.12.2019

Kabul Tarihi: 11.12.2019

\section{Özet}

Dünya yağlı tohumlar üretiminde soya ve palm bitkisinden sonra \%12.27'lik pay ile 3. sırada, bitkisel yağ üretiminde de \%14.44 ile yine 3. sırada yer alan kanola, Türkiye'de yağlı tohumlar üretiminde \%4.63, bitkisel yağ üretiminde de $\% 6.36^{\prime}$ lık paya sahiptir. Kanola üretimi, gelişen dünyanın aksine Türkiye'de, uygulanan çeşitli destekleme politikalarına rağmen yeterince gelişme gösterememiştir. Buna rağmen ülkede son 30 yıllık dönemde birim alandan elde edilen verim değerinde en yüksek artış kanoladan sağlanmıştır. 2018 yılında Türkiye'nin kanola üretiminde \%7.5'lik pay ile Çanakkale ili 5. sırada yer almıştır. Araştırma alanı olarak belirlenen ilde Tam Sayım Yöntemine göre belirlenen 83 tarım işletmesinden elde edilen veriler yardımıyla kanola üretimi fonksiyonel analiz yönüyle incelenmiştir. Birim alandan ortalama $296 \mathrm{~kg} / \mathrm{da}$ kanola elde edebilmek için yaklaşık olarak; $450 \mathrm{~g}$ tohum, $26 \mathrm{~kg}$ saf gübre, $330 \mathrm{cc}$ tarımsal mücadele ilacı ve 13 I mazot kullanımına ihtiyaç duyulmaktadır. Kanola üretimine ilişkin oluşturulan fonksiyonda; gübre masrafı $\left(\mathrm{X}_{1}\right)$, tarımsal mücadele ilacı bedeli $\left(X_{2}\right)$ ve tohum bedeli $\left(X_{3}\right)$ faktörlerinin üretim elastikiyetleri \%5 ihtimal düzeyinde önemli bulunmuş, denklemin üretim elastikiyetleri katsayıları toplamının $\left(\sum \beta_{i}: 1.004\right)$ ise ölçeğe artan getiriyi ifade ettiği sonucuna varılmıştır. Oluşturulan denklemde yer alan faktörler arasında marjinal etkinlik katsayısı en yüksek değişken 13.94 ile tarımsal mücadele ilacı masrafı $\left(\mathrm{X}_{2}\right)$ olarak bulunmuştur.

Anahtar kelimeler: Kanola, fonksiyonel analiz, Çanakkale.

\section{Functional Analysis of Canola Production in Çanakkale Province}

\begin{abstract}
Canola takes $3^{\text {rd }}$ place after soybean and palm in global oil seeds production with a percentage of $12.27 \%$, and it is in $3^{\text {rd }}$ place in vegetable oil production with a percentage of $14.44 \%$. In terms of Turkey, canola's proportional share in oil seeds production is $4.63 \%$, and it is $6.36 \%$ in vegetable oil production. Despite some agricultural subsidy policies for throughout the years, Turkey's canola production has not increased enough. However, for the last three decade, canola has shown the most improvement in productivity for unit area. Çanakkale City was $5^{\text {th }}$ in Turkey's canola production in 2018 with a proportional share of $7.5 \%$. In this study, canola production in Çanakkale City was examined in terms of functional analysis with the data, which were obtained from 83 agricultural enterprises. According to the research results, canola production takes the first place in vegetative production pattern with a share of $31 \%$. The average canola production area was 84.07 $\mathrm{da}$, and the average productivity was found as $296.20 \mathrm{~kg} / \mathrm{da}$. In order to obtain $296 \mathrm{~kg} / \mathrm{da}$ of canola, it is necassary to use; $450 \mathrm{~g}$ seed, $26 \mathrm{~kg}$ pure fertilizer, $330 \mathrm{cc}$ agricultural pesticide and $13 \mathrm{I}$ diesel fuel. It is found out that from the function formula of canola production; production elasticities of fertilizer cost $\left(X_{1}\right)$, pesticide cost $\left(X_{2}\right)$ and seed cost $\left(X_{3}\right)$ were found significant at the level of $5 \%$ error margin, and total production elasticities from the formula $\left(\sum \beta_{i}: 1.004\right)$ indicates that increasing returns to scale. Among the factors that is belong to the equation, marginal efficiency coefficient was found highest in pesticide cost $\left(\mathrm{X}_{2}\right)$ which was 13.94 .
\end{abstract}

Key words: Canola, functional analysis, Çanakkale. 


\section{Giriş}

Türkiye, tarımsal üretim potansiyeli yüksek ülkeler arasında yer almasına rağmen, uygulanan farklı tarımsal destekleme politikaları nedeniyle günümüzde önemli miktarda döviz ödeyerek tarımsal ürünler ve türevlerinin alımında bulunmaktadır. Bu ürün gruplarının başında yağlı tohumlar ve türevleri gelmektedir. Türkiye'nin tarımsal dış ticareti incelendiğinde, 2016 yılında yaklaşık 3.2 milyar \$ ile yağlı tohumlar ve türevlerine ödeme yapıldığı anlaşılmaktadır (Kadakoğlu ve Karlı, 2019).

2017 yılı verilerine göre dünya yağlı tohumlar üretimi yaklaşık 824 milyon ton olarak gerçekleşmiştir. Üretimde $\% 42.8$ ile soya ilk sırada yer alırken bu ürünü \%38.5 ile palm ve \%12.27 ile kanola izlemiştir (FAO, 2019). 2018 yılı Tüik verilerine göre Türkiye'de yağlı tohumlar üretimi yaklaşık 4 milyon ton olup; ilk sırayı \%48.62 ile yağlık ayçiçeği alırken, \%4.63 ile kanola (pamuk çiğidi ve yerfıstığından sonra) 4. sırada yer almıştır. Bu veriler Türkiye'de genelde yağıı tohumlar özelde ise kanola üretiminin bitkisel üretim deseninde çeşitli nedenlerden dolayı istenilen oranda pay alamadığını ortaya koymaktadır (TÜiK, 2019). Araştırma öncesi yapılan literatür taramasında Türkiye'de kanola üretiminin fonksiyonel analizine dayalı bir çalışmaya rastlanılmamıştır. Bu çalışma ile Çanakkale ilinde kanola üreten 83 işletmeden derlenen veriler yardımıyla kullanılan girdiler ile elde edilen ürün arasındaki ilişki fonksiyonel olarak incelenmiştir. Çalışmanın son bölümünde araştırma alanında kanola üretiminin artırılmasına yönelik önerilerinde bulunulmuştur.

\section{Materyal ve Yöntem}

Araştırmanın ana materyalini, Çanakkale ilinde kanola üreten tarım işletmelerinden 2018 yılı Kasım ayında yürütülen anket çalışmaları sonucunda elde edilen veriler oluşturmaktadır. Araştırmanın ikincil verilerinin temininde ise; başta Birleşmiş Milletler Gıda ve Tarım Örgütü (FAO), Tarım ve Orman Bakanlığı (TOB), Türkiye İstatistik Kurumu (TÜiK) yayınları ve elektronik ortam verilerinden faydalanılmıştır.

Örneğe girecek işletme sayılarının belirlenmesi aşamasında Çanakkale Tarım ve Orman il Müdürlüğü Çiftçi Kayıt Sistemi (ÇKS) verilerinin incelenmesi sonucu 2016-17 üretim döneminde 6 ilçede 41 tarım işletmesinde 3.679 da alanda kanola üretimin yapıldığı tespit edilmiştir. Bu nedenle araştırmada "Tam Sayım Yöntemi" kullanılarak ÇKS'ye kayıtlı 41 işletmeyle birlikte il genelinde ulaşılabilen işletmelerin tamamıyla anket uygulaması gerçekleştirilmeye çalışılmıştır. Bu aşamada anket uygulanan köyler ve üreticilerin belirlenmesinde Çanakkale Tarım ve Orman il ve İlçe Müdürlüğü yöneticileri ile teknik personelinden üst düzeyde faydalanılmasına gayret gösterilmiştir.

Araştırmada Cobb-Douglas tipi fonksiyon kullanılarak analizler yapılmıştır. Konu ile ilgili kaynaklarda bu fonksiyon tipinin tarımsal üretime yönelik olarak yapılan ekonometrik analiz çalışmalarına uygun düştüğü belirtilmektedir (Heady ve Dillon, 1966; Zoral, 1984; Özçelik, 1989). Ana kitleye ait denklem;

$$
Y=a X_{1}^{b 1} X_{2}^{b 2} X_{3}^{b 3} \ldots X_{n}^{b n}
$$

şeklindedir. Denklemin iki tarafının da logaritması alındığında denklem;

$$
\begin{gathered}
\log Y=\log \alpha+\beta 1 \log x 1+\beta 2 \log x 2+\ldots+\beta k \log x k \\
+e^{u}
\end{gathered}
$$

şeklinde oluşmaktadır. Fonksiyondaki $\beta_{i}$ değerleri üretim elastikiyetlerini göstermektedir $\left(\beta_{i}=1,2, \ldots . n\right) . \beta_{i}$ değerlerinin testi,

$$
t \beta i=\beta i / \operatorname{se}(\beta i)
$$

Formülü kullanılarak yapılmakta ve elde edilen $\mathrm{t} \beta_{i}$ değeri, "t-tablosu" nda (n-k-1) serbestlik derecesini gösteren satır ile istenen önem seviyesine ait sütunun kesiştiği yerdeki değeri ile karşılaştırılmaktadır.

Regresyon denklemine ait; çoklu regresyon (R) ve determinasyon katsayısı $\left(R^{2}\right)$, bağımsız değişkenlere ait elastikiyet katsayıları $(\beta i)$, standart hataları (se $\beta i$ ) ve önem seviyeleri (t $\beta i$ ), değişkenlerin geometrik ortalamaları $\left(X_{i} G, Y G\right)$, basit korelasyon katsayıları $\left(r_{j}\right)$ ile denklemin standart sapması (S) ve önem seviyesi ( $F$ değeri) uygun bir istatistik paket programı yardımıyla yapılan regresyon analizleri sonucunda elde edilmiştir.

Çalışmada kanola üretiminde kullanılan girdilerin Marjinal Gelirinin (MG) tespit edilmesinde altta belirtilen formül kullanılmıştır (Karagölge 1973).

$$
M j G x j=\beta j \frac{Y G(\text { ort })}{X j G(\text { ort })} F y
$$

Üretim girdilerinin Marjinal Etkinlik Katsayısının (MEK) saptanmasında kullanılan formül aşağıda gösterilmiştir (Akçay ve Uzunöz 1999).

$$
\begin{aligned}
& M E K \\
& =\frac{\text { Faktörlerin Marjinal Geliri }}{\text { Faktörlerin Marjinal Masrafı(Faktör Fiyatı) }}
\end{aligned}
$$


Tahmin denkleminde yer alan değişkenlerin $\left(\mathrm{X}_{\mathrm{i}}\right)$ marjinal verimi;

$$
\operatorname{MVXi}=\beta \mathrm{i} * Y G / X i G
$$

formülü kullanılarak belirlenmiştir (Zoral, 1973). Ekonomik optimum için marjinal gelirler, faktör fiyatlarına bölünerek etkinlik katsayıları (MEK $\mathrm{X}_{\mathrm{i}}$ ) saptanmıştır (Dilmen, 1985).

Faktörler arasındaki teknik ikame haddi (marjinal teknik ikame oranı),

$$
\text { MTIO } x 1 / x 2=\frac{X 2 G \text { Marjinal Verim }}{\text { X1GMarjinal Verim }}
$$

veya;

$$
\text { MTIO } x 1 / x 2=\mathrm{b} 2 . \mathrm{X} 1 \mathrm{G} / \mathrm{b} 1 . \mathrm{X} 2 \mathrm{G}
$$

formülleri kullanılarak belirlenmiştir (Gündoğmuş,1998).

\section{Bulgular ve Tartışma}

Araştırma kapsamında Çanakkale ilinde faaliyet gösteren 83 tarım işletmesinden derlenen veriler yardımıyla; kanola üretim değeri ile üretimde kullanılan girdiler arasındaki ilişkiler Cobb-Douglas tipi fonksiyon kullanılarak analiz edilmiştir (Doll ve Orazem 1984; Beattie ve Taylor 1987, Neill, 2002). Kanola üretimine ait fonksiyonda yer alan değişkenler;
$\mathrm{Y}=$ Gayrisafi üretim değeri (GSÜD); Kanola üretim miktarı ile ürüne ait çiftlik avlusu fiyatının çarpılmasıyla bulunmuştur.

Bağımsız değişkenler ise şunlardır;

$\mathrm{X}_{1}=$ Kimyasal gübre bedeli (TL/da),

$\mathrm{X}_{2}=$ Tarımsal mücadele ilacı bedeli (TL/da).

$\mathrm{X}_{3}=$ Üretimde kullanılan tohum bedeli (TL/da)

Kanola üretiminde bağımlı değişken (Y) ile bağımsız değişkenler arasındaki $\left(X_{i}\right)$ fonksiyonel ilişki;

$$
\begin{aligned}
& Y=1,281 * X_{1}{ }^{0,662 *} X_{2}{ }^{0,110} * X_{3}{ }^{0,232} \\
& \left(S=0,131 ; R=0,922 ; R^{2}=0,919\right) \\
& \text { olarak tespit edilmiştir. }
\end{aligned}
$$

Denklemin çoklu korelasyon katsayısı ve determinasyon katsayısı $\left(F_{\text {hesap }}>F_{\text {tablo }}\right.$ ) \%1 ihtimal düzeyinde önemli bulunmuştur (Çizelge 1). Determinasyon katsayısına göre, kanolaya ilişkin üretim değerindeki değişmelerin yaklaşık \%92'sini, denklemde yer alan bağımsız değişkenlerle açıklanabildiği ve seçilen fonksiyon tipinin uygun olduğu belirtilebilir. Çalışmada otokorelasyon varlığının belirlenmesi için Durbin Watson (DW) istatistiği kullanılmış olup, belirlenen denkleme ilişin DW hesap değerinin 1,606 olarak hesaplanması sebebiyle pozitif otokorelasyon testi uygulanmıştır (Özçelik, 1994). Uygulanan test sonucunda elde edilen fonksiyon için pozitif korelasyon olmadığı $\left(D W_{h} 1,606>D_{U}(0,01) 1,578\right)$ sonucuna varılmıştır.

Çizelge 1. Kanola üretim fonksiyonu varyans analiz tablosu.

\begin{tabular}{lccccc} 
& Serbestlik derecesi & Kareler toplamı & Kareler ortalaması & F değeri & P değeri \\
\hline Regresyon & 3 & 16.064 & 5.355 & 312.79 & 0.000 \\
Kalan & 79 & 1.352 & 0.017 & & \\
Toplam & 82 & 17.416 & & & \\
\hline
\end{tabular}

Çizelge 2. Üretim faktörlerine ait üretim elastikiyetleri.

\begin{tabular}{lcccc} 
& $\begin{array}{c}\mathbf{X}_{\mathbf{1}} \\
\text { (gübre) }\end{array}$ & $\begin{array}{c}\mathbf{X}_{\mathbf{2}} \\
\text { (tohum) }\end{array}$ & $\begin{array}{c}\mathbf{X}_{\mathbf{3}} \\
\text { (ilaç) }\end{array}$ & $\left(\boldsymbol{\Sigma} \boldsymbol{\beta}_{\mathrm{i}}\right)$ \\
\hline Üretim elastikiyetleri $\left(\beta_{\mathrm{i}}\right)$ & 0.662 & 0.110 & 0.232 & 1.004 \\
Standart hata $\left(\mathrm{s}_{\mathrm{e}} \beta_{\mathrm{i}}\right)$ & 0.080 & 0.030 & 0.075 & - \\
$\mathrm{t} \beta_{\mathrm{i}}$ & $7.821^{*}$ & $2.309^{*}$ & $3.180^{*}$ & - \\
\hline
\end{tabular}

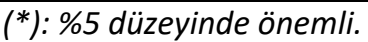

Bağımsız değişkenlere ait üretim elastikiyetleri incelendiğinde 3 faktörün de üretim elastikiyeti katsayılarının pozitif karakterli olduğu görülmektedir (Çizelge 2). Bu durum hangi faktörün azaltılması veya artırılmasının gerekli olduğu konusunda sonuçlar çıkarılmasını olanaklı kılmaktadır ( Heady ve Dillon, 1966; Zoral, 1973; Özçelik, 1989).

Elde edilen denklemde kullanılan girdilerin üretim elastikiyeti katsayısı pozitif işaretli olması nedeniyle üretimde kullanılan faktörler için ekonomik optimum noktası belirlenebilmektedir (Rehber ve Erkuş, 1984). Kanola üretiminde kullanılan girdilerin üretim elastikiyetleri katsayıları toplamı $\left(\sum \beta_{i}\right) 1,004$ olup, ölçeğe göre artan getiri söz konusudur. Kısacası, kanola üretiminde tohum, gübre ve ilaç girdilerine yapılan harcama \%1 artırıldığında, üretim değeri \%1'in biraz üzerinde de olsa artış göstermektedir. 
Gübre bedeli $\left(X_{1}\right)$, ilaç bedeli $\left(X_{2}\right)$ ve tohum bedeline $\left(X_{3}\right)$ ait faktörlerin üretim elastikiyetleri \%5 düzeyinde önemli bulunmuştur. Kanola üretimi için harcanan gübre girdisindeki \%10'luk artışın kanola gelirini \%6,60; ilaç girdisindeki \%10'luk artışın kanola gelirini $\% 1,10$ ve tohum girdisindeki \%10'luk artış kanola gelirini \%2,30 oranında artıracağı ifade edilebilir. Fakat bu durumu faktör kullanımına yönelik harcamaların yükseltilmesiyle kanola üretim değerinde de artış görülebileceği şeklinde yorumlanmamalıdır. Zira, "girdi için yapılan harcamalar arttıkça GSÜD bu yapılan harcamaların artış oranından az da olsa daha fazla artacaktır" şeklinde bir ifade daha uygun ve doğru olacaktır. Bu nedenle yapılacak yorumun; kanola üretiminde daha kaliteli ve nitelikli girdi kullanımı için harcanan paradan biraz daha yüksek düzeyde (ölçeğe artan getiri) ürünün GSÜD’nde artışa neden olabileceğini belirtmek daha sağlıklı olacaktır.

Girdilere ilişkin üretim elastikiyetleri toplamı $\left(\Sigma \beta_{\mathrm{i}}\right) 1.004$ olarak bulunmuştur. Bu durum ölçeğe artan getiriyi ifade etmektedir. Elde edilen fonksiyonda en yüksek marjinal ürün değeri 15.75 $\mathrm{TL}$ ile ilaç $\left(\mathrm{X}_{3}\right)$ girdisine aittir. Bu değişkeni $10.61 \mathrm{TL}$ ile gübre girdisi $\left(X_{1}\right)$ ve 5.74 ile tohum girdisi $\left(X_{2}\right)$ girdisi izlemektedir (Çizelge 3).

Çizelge 3. Model katsayılarının marjinal kıymetleri ve etkinlik katsayıları.

\begin{tabular}{lcccc} 
& $\begin{array}{c}\mathbf{X}_{\mathbf{1}} \\
\text { (gübre) }\end{array}$ & $\begin{array}{c}\mathbf{X}_{\mathbf{2}} \\
\text { (tohum) }\end{array}$ & $\begin{array}{c}\mathbf{X}_{\mathbf{3}} \\
\text { (ilaç) }\end{array}$ & $\mathbf{Y}$ \\
\hline Geometrik ortalama & 2885.54 & 886.88 & 680.95 & 22666.25 \\
Üretim faktörlerinin marjinal ürün kıymeti & 10.61 & 5.74 & 15.75 & - \\
Faktör fiyatları (TL) & 1.13 & 1.13 & 1.13 & - \\
Marjinal etkinlik katsayısı & 9.39 & 5.08 & 13.94 & - \\
\hline
\end{tabular}

Çizelge 4. Faktörlerarası Marjinal Teknik Ikame ve Fiyat Oranları

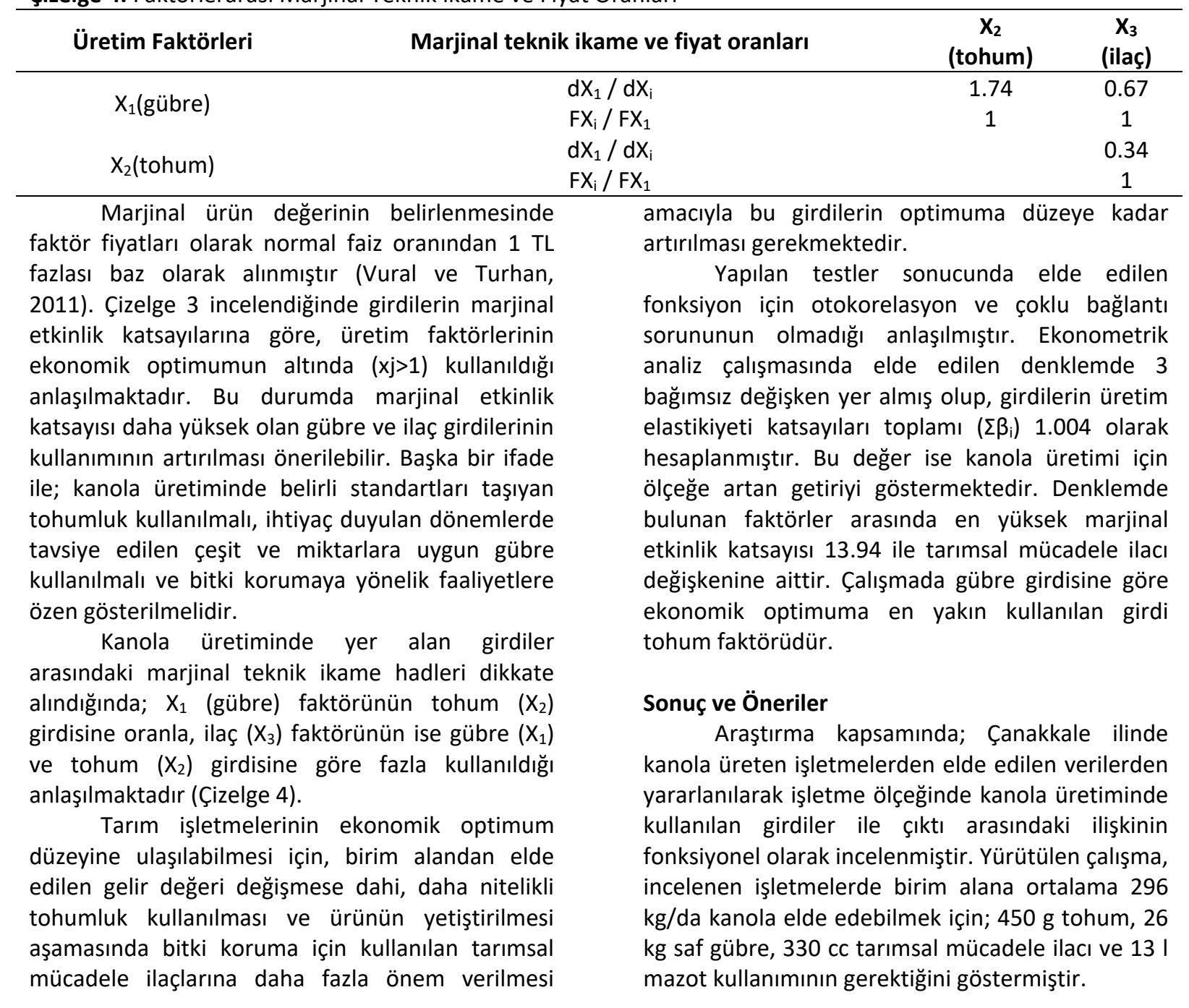


Araştırmada Çanakkale il genelinde 83 işletmeden derlenen veriler yardımıyla; kanola üretim değeri ile üretimde kullanılan girdiler arasındaki ilişkiler analiz edilmiştir. Oluşan fonksiyonda gübre bedeli $\left(X_{1}\right)$, ilaç bedeli $\left(X_{2}\right)$ ve tohum bedeline $\left(X_{3}\right)$ ait girdilerin elastikiyet katsayıları \%5 düzeyinde önemli bulunmuş olup, denkleme ait üretim elastikiyetleri katsayıları toplamı $\left(\sum \beta_{i}:\right.$ 1,004) ölçeğe artan getiriyi ifade etmektedir. Denklemde yer alan 3 değişkene ait marjinal etkinlik katsayıları 5-14 aralığında bulunmuştur.

Yürütülen araştırma Çanakkale ilinde üreticilerin kanola üretimine olumlu yaklaştığını göstermekle birlikte; üretimin kuru alanlarda yapılması, sertifikalı tohumluk kullanımına önem verilmemesi, hasat alanlarına yeterince biçerdöverin girememesi, girdi fiyatlarının ürün fiyatından daha yüksek düzeyde artış göstermesi, işletmelerin yeterince tarımsal üretimde kullanabileceği sermayelerinin olmaması, kanola üretimine verilen desteklerin birim fiyatlarının yetersiz bulunması, ilde önemli sayıda üreticinin genelde tarımsal üretimde özelde ise kanola üretiminde verilen destekleri çeşitli nedenlerden dolayı alamamaları bu ürünün ilde gelişim seyrini önemli derecede ve olumsuz yönde etkilediklerini ortaya koymuştur. Bu sebeple, incelenen işletmelerde kanola üretiminin artırılabilmesi için mutlaka sulu alanlarda üretimin yaygınlaştırılması, sertifikalı tohumluk kullanımının özendirilmesi ve girdi kullanımında bilinç düzeyinin yapılacak olan eğitim çalışmalarıyla artırılması gerekmektedir.

Teşekkür: Araştırma, Çanakkale Onsekiz Mart Üniversitesi Bilimsel Araştırma Projeleri Koordinasyon Birimi'nce Hızlı Destek Projesi (Proje No: FHD-2018-2664) kapsamında desteklenmiştir.

\section{Kaynaklar}

Akçay, Y., Uzunöz, M. 1999. Tarım İşletmelerinde Kaynak Kullanımı Etkinliği Üzerine Bir Araştırma: Niksar Ovası Örneği. Tarım ve Mühendislik Dergisi. 59: 29-38.

Beattie B.R., Taylor, C.R. 1987. The Economics of Production, John Wiley and Sons Inc., New York.

Dilmen, B. 1985. Bağcılıkta Kullanılan Üretim Faktörlerinin Çeşitli İşletme Büyüklükleri Üzerindeki Etkileri ve Bu İşletme Gruplarının Birbirleriyle Karşılaştırılması: Gaziantep illi Bağcılığının Ekonometrik Analizi. MPM Verimlilik Dergisi, Ankara, (2) 86-108.

Doll J.P., Orazem, F. 1984. Production Economics Theory with Applications, John Wiley and Sons Inc., New York.
FAO, 2019. Bitkisel üretim istatistikleri. (erişim: http://www.fao.org) (erişim tarihi: 29.07.2019)

Gündoğmuş, E. 1998. Ankara i̇li Akyurt İlçesi Tarım İşletmelerinde Ekmeklik Buğday (Triticum aestivum L.) Üretiminin Fonksiyonel Analizi ve Üretim Maliyetinin Hesaplanması. Tr. J. of Agriculture and Forestry. 22: 251-260.

Heady, O.E., Dillon, J.L. 1966. Agricultural Production Functions. Iowa State University Press, USA.

Kadakoğlu,B., Karlı, B. 2019. Türkiye'de Yağı Tohum Üretimi ve Dış Ticareti. Akademik Sosyal Araştırmalar Dergisi, 7 (96) 324-341.

Karagolge, C. 1973. Arazi Tasarruf Şekillerine Göre Erzurum illindeki Tarım İşletmelerinin Ekonometrik Analizi. Ankara Ün. Yay. No:312. Ziraat Fak. Yay. No:153, Arş. Seri No:90, Sevinç Matb., Ankara, s.8-24.

Neill, R.J. 2002. Production and Production Functions: Some Implications of a Refinement to Process Analysis", Journal of Economic Behaviour \& Organization. 51(4) 507-521.

Özçelik, A. 1989. Ankara Şeker Fabrikası Civarındaki Seker Pancarı Yetiştiren Tarım İşletmelerinde Şeker Pancarı İle Buğday İçin Fiziki Üretim Girdileri ve Üretimin Fonksiyonel Analizi A.Ü. Ziraat Fakültesi Yayın No:1113, Ankara, 1989.

Özçelik, A. 1994. Ekonometri. A.Ü. Ziraat Fak. Yay. No:1323, Ders Kitabı No:382, s.148-156, Ankara.

Rehber E., Erkuş, A. 1984. Nevşehir'de Patates Üreten Tarım İşletmelerinin Ekonomik Analizi. Ankara Üniversitesi, No TE 1, Ankara.

TÜiK, 2019. Veritabanı/Tarım/Bitkisel Üretim İstatistikleri. (yağlı tohumlu bitkiler üretim bilgileri). (erişim: https://biruni.tuik.gov.tr/medas/?kn=92\&lo cale=tr, Erişim tarihi: 05.07.2019).

Vural, H., Turhan, Ş. 2011. Bursa Ilinde Şeftali Üretiminin Ekonometrik Analizi. U. Ü. Ziraat Fakültesi Dergisi. 25 (2) 1-6.

Zoral, K. 1973. Cobb-Douglas Üretim Fonksiyonunun Yukarı Pasinler Ovasındaki Patates Üretimine Uygulanması. Atatürk Üniversitesi Yayınları No:303, Sevinç Matbaası, Ankara.

Zoral, K. 1984. Üretim Fonksiyonları. Dokuz Eylül Üniversitesi Mühendislik Mimarlık Fakültesi Yayınları (MM/END-84 EY 052), İzmir. 